\title{
Study on the Use of Modal Verbs in IWriteBaby Corpus-Taking "Can" and "Could" as Examples
}

\author{
Bilian Zan \\ Southwest Petroleum University, Chengdu 610500, Sichuan, China
}

\begin{abstract}
Modal verbs are frequently used in English argumentative writing, especially Can and Could, but Chinese English learners are prone to making mistakes when using them. Therefore, based on the IWriteBaby corpus, this paper explores the use of these two of modal verbs in Chinese English learners' argumentative writing in order to provide theoretical guidance for English argumentative teaching. It is found that Chinese English learners frequently use the negative forms to guide the readers to think critically and limit the space for discourse dialogue, thus achieving the communicative purpose of writing.
\end{abstract}

Keywords: Argumentative writing, Modal verbs, Can and Could, IWriteBaby corpus.

\section{Introduction}

The Australian linguist Martin had enriched the interpretation of interpersonal meaning of discourse in Halliday's systemic functional linguistics, thus forming the evaluation system concerned with interpersonal relationship. As Martin points out, "The evaluation system focuses on how the speaker expresses his or her position through discourse, thus interacting with the potential reader, and finally persuading the reader." ${ }^{\text {[1] }}$ In recent years, many scholars have begun to apply appraisal theory to English teaching research. After collecting and sorting out the literature, the research scope can be divided into the following three aspects. First, some scholars concentrate on the study of Chinese English learners' English argumentative writing. Dong Lianqi and Victor-Gabriel Lemaire explored the characteristics of Chinese English learners' writing assessment resources based on corpus, but the study only focused on the overall distribution and there is no reference to the specific features of a lexical chunk or phrase collocation ${ }^{[2]}$. Then Dong Lianqi further studied the intervening lexical chunks in Chinese English learners' argumentative writing under the appraisal system, which has provided a new perspective for the study of argumentative writing ${ }^{[3]}$. The second is about the collocation of modal verbs in Chinese English learners' argumentative writing. Meng Qingnan and Luo Weihua summarized the modal construction "Need (to) V" and found that there are three main factors affecting the type selection of the infinitive complement, which has enriched the study of the construction of modal verbs ${ }^{[4]}$. Finally, the contrastive studies about modal verbs are mainly focused by some scholars. Gao Xia did a contrastive study of modal verbs between Chinese and western learners' academic writing and found there are significant differences between them in the use of modal verbs and collocations they frequently use ${ }^{[5]}$.

In conclusion, the corpus-based study of Chinese English Learners' argumentative writing mainly focuses on the overall distribution of the research content, and the study on specific vocabularies or collocations are limited. Although most scholars have made a comparative study of modal verbs from different perspectives, the use of this two modal verbs is less studied based on the writing corpus. In view of this, this paper discusses the Chinese English Learners' usage of these two modal verb so that it can provide theoretical guidance for the teaching of these two English modal verbs based on the IWriteBaby corpus published by Professor Xu Jiajin ${ }^{[6]}$.

\section{Theoretical Framework}

Since the 1990s, linguists represented by Australian linguist Martin have extended and enriched the interpretation of interpersonal meaning of discourse in Halliday's functional linguistics, thus forming a focus on interpersonal relationships. This theoretical system mainly focuses on how speakers express their positions with the help of words, so as to communicate with potential readers, and finally achieve the purpose of persuading readers. In addition, the evaluation system contains three subsystem. Each system is interconnected and has different functions. And this paper takes the intervention system as the perspective and analyze the distribution characteristics of these two modal "can" and "could" in the corpus.

\section{Research Design}

\subsection{Corpus Source}

This study is based on the IWriteBaby corpus which has 8 million words, published by Professor Xu Jiajin of Peking University in the sub-forum of the fourth national high-level forum on the Reform and development of foreign language education in China. The reasons why the author chooses this corpus as research subject are as follows. Firstly, the corpus has a large capacity and it includes English compositions from students from 69 universities in China, of which the ratio of key universities to ordinary universities is about $1: 10$. Secondly, the coverage area is wide and the corpus is quite comprehensive. The last reason is that these students have different majors and come from 154 different majors, which is conducive to comparative analysis and research.

\subsection{Research Questions}

This paper studies the usage of these two modal verbs "can" and "could" from the perspective of appraisal theory, aiming to explore the distribution of these two modal verbs in Chinese English learners' English argumentative writing. The questions to be studied are as follows: 
(1) What are the characteristics of the total number and distribution of modal verbs "can" and "could" in the corpus?

(2) What are the characteristics of different collocations of modal verbs "can" and "could" in the corpus?

(3) What are the features of the classification, pragmatics and certainty distribution of the different collocations of modal verbs "can" and "could" in the corpus?

(4) According to these features, what English teachers should do to improve the quality of the English argumentative writing teaching about the use of these two modal verbs?

\section{Analysis and Discussion of Results}

\subsection{The General Features of the Distribution of "Can" and "Could"}

First, after using the test type as a search subject in the IWriteBaby corpus, it's obvious that the total frequency of the modal verb "can" is 89694 times. This shows that English learners in China often use the modal verb "can" to express their opinions in English argumentative writing. In addition, the frequencies of the distribution of "can" in three aspects: class tests, writing after class, and school exams, are different. And their respective percentages of their total frequency are $13.39 \%, 54.7 \%$, and $31.2 \%$. Among them, the modal verb "can" appears most frequently in the writing after class. This also shows that Chinese English learners use "can" more casually in ordinary English writing after class, and at the same time they to a large extent do not think carefully about whether the use of "can" is correct or not.

When it comes to the modal verb "could" in the corpus, this is also different but slightly similar to the modal verbs "can" in the corpus. When the author uses the modal verb "could" as the research subject in the corpus, it is finally found that the total frequency of the modal verb "could" is 5866 times. Apparently, it's less than the total frequency of the modal verb "can". Compared with the frequency of "can". In other words, Chinese English learners are likely to use the modal verb "can" to express their opinions in English argumentative writing rather than choosing the modal verb "could". In addition, the percentages of class tests, writing after class, and school exams could account for $13.18 \%, 57.55 \%$, and $29.27 \%$ of their total frequency respectively. Similarly to the use of the modal verb "can", the modal verb "could" appear most frequently in the writing after class.

The reasons why the frequency of the modal verb "can" and "could" is different but slightly similar lie in three aspects. The first one that the author wants to emphasize is that maybe the Chinese English learners are used to using these two modal verbs to express their ideas about the topic in English argumentative writing. Because these two modal verbs are the first group modal verbs that most Chinese English learners start to learn how to use them correctly. The second one is that Chinese English learners are likely to form this kind of fixed pattern of thinking that they are always incline to choosing these two modal verbs when they want to use modal verbs to express some possibilities or something else in English argumentative writing. The last one is that Chinese English learners are poor in using various vocabularies and collocations to replace what they've used in English argumentative writing.

\subsection{The General Features of the Distribution of the Different Collocations of "Can" and "Could"}

According to the general features of the distribution of "can" and "could", it can be known that Chinese English learners mostly choose these two modal words to talk about their ideas during the process of English argumentative writing. As result, the author plans to delve into the general features of the distribution of the different collocations of "can" and "could", which aims to find how Chinese English learners use the different collocations of these two modal verbs. After finishing the research, the results of different collocations of these two modal verbs in the corpus were shown in the Table 1 respectively. It can be seen that three aspects: class tests, writing after class and school exams are included in this Table 1 and the frequency number of each aspect varies differently. And there are six different collocations of modal verb of "can" and "could", which can give a brief overlook of how often Chinese English learners use these different collocations in the corpus. From what the author has collected before the research, a comprehensive and careful analysis of different collocations of these two modal verbs is going to give.

Table 1: General characteristics of the distribution of different collocations of These Two Modal Verbs

\begin{tabular}{|c|c|c|c|c|c|c|}
\hline $\begin{array}{c}\text { Collocation } \\
\text { forms }\end{array}$ & Can' t & Can Be & Can't be & Couldn't & Could Be & $\begin{array}{c}\text { Couldn't } \\
\text { be }\end{array}$ \\
\hline $\begin{array}{c}\text { Frequency } \\
\text { Number }\end{array}$ & 7107 & 5405 & 828 & 526 & 467 & 38 \\
\hline Class Tests & 1012 & 866 & 163 & 65 & 74 & 5 \\
\hline $\begin{array}{c}\text { Writing After } \\
\text { Class }\end{array}$ & 3848 & 3262 & 490 & 293 & 291 & 25 \\
\hline School Exams & 2247 & 1277 & 175 & 168 & 102 & 8 \\
\hline
\end{tabular}

From the Table 1, the order of the frequency of the collocation of these two modal verbs is: Can't > Can be > Can't, which indicates that Chinese English learners use "Can't" most frequently in their English writing. However, in class tests and writing assignment, Chinese English learners usually choose the negative form to explain their ideas. As a result, it can be concluded that Chinese English learners use modal verbs more frequently, but their collocations are less abundant. Therefore, the question that why Chinese English learners don't use different collocations of these two modal verbs comes here. To answer the question well, the first step is that specific features of different collocations of modal verb "can" and "could" should be analyzed.

\subsection{The Specific Features of the Different Collocations of Modal Verb "Can" and "Could"}

\subsubsection{Classification features}

There are three systems in the evaluation system and the engagement system is one of the important components. It's a system that mainly focuses on how the author interacts and negotiates with opinions or voices outside of himself in order to clarify his position. It's divided into two aspects: expansion and compression. First of all, expansion refers to allowing readers to express different positions or attitudes, which can be achieved by initiating and extracting. Second, compression 
refers to the author's prevention or restriction of readers, expressing his views through abstentions and declarations. The modal verbs "can" and "could" have many meanings in English grammar, and at the same time they have different semantic and pragmatic functions in different contexts. From what the author has found before, Chinese learners not only often use the negative forms of the modal verbs "can" and "could" to communicate with readers, but also use both of them to express the meaning of speculation. In view of this, this paper analyzes their different collocations of these two modal verbs in different context based on the engagement system

The types of modal verbs "can" and "could" in Chinese English learners' writing can be divided into two categories. One is that Chinese English learners choose the negative forms of these two modal verbs to restrict the readers so as to illustrate their own points of view. The other one is that Chinese English learners expand the collocation forms of these two modal verbs to allow readers to hold their own views by expanding the possibilities, which indirectly persuades the readers to agree with their own views and finally achieves the purposes of verbal communication. However, how they represent differently in the certain context when Chinese English learners use them. In the next part, the author will going to discuss the pragmatic features of these two modal verbs in the various contexts and roughly explore there are how many kinds of pragmatic features based on the data that the author has collected before.

\subsubsection{Pragmatic features}

Although Chinese English learners use different collocations of these two modal verbs to expess their ideas about the topic, the classification features of this two modal verbs have different pragmatic features in different contexts. Therefore, the third level is chosen to be the research subject and its pragmatic meaning is analyzed. Finally, it is found that there are two different pragmatic functions: persuasive function and heuristic function.

\section{a) Persuasive Function}

The two modal verbs both have the Chinese meaning that someone is able to do something. And Chinese English learners often choose to communicate with their readers in the negative form, whose aim is to persuade the reader to support his or her ideas in the course of verbal communication. After the careful analysis of different sentences, it's apparent that there are two kinds of aspects in terms of persuasive function.

The first one aspect in the persuasive function is that Chinese English learners use "can" and "could" to show that it's possible for someone to do something or something to happen in dairy life. In brief, Chinese English learners use them to express abilities. But, this kind of meaning also consist in three different contexts. And the author will expound on them one by one.

In the first context, the modal verbs "can" and "could" are used to refer to the ability that is from abstract nouns, such as strength, knowledge and intelligence. Here are some examples.
1) If you eat healthy food and vegetables, you could become better than before.

2) On the other hand, there is no doubt that keeping a balanced diet in your dairy life can makes you become healthy and strong.

3) Every man who is healthy on the planet can walk for at least six years every day.

From these three examples above, it's obvious that "can" is chosen in the sentence to limit and imply the readers to make a choice that is similar to themselves. And in this way the writer can achieve the goal that allows readers to accept the writers' ideas in their argumentative writing. In the first and second example, the writer uses the word "can" to indicate that healthy food and vegetables are the key to becoming healthy and stresses the importance of keeping a balanced diet in our daily life. In fact, the modal verb "can" implies the ability that people can gain fruitful benefits from healthy food and vegetables, especially the strength. And in the second example, the modal verb "can" denotes the ability that man has the intelligence to know how to control our body.

In the second context, the modal verbs "can" and "could" are used to refer to the ability that someone is willing to help others do something. And there are two examples for this kind of explanation.

4) If you often try your best to help others, they can help you in need all the time.

5) If you spent much time communicating with your parents when you were upset in the past., they could be your man you can talk to when you are in trouble next time.

From these two examples, the writer uses the modal verb "can" to persuade the readers to accept this kind of situation that you can get some help from others, such as your friends, sisters, and parents if you do something for them, and they also are willing to help you.

In the last context, the modal verbs "can" and "could" are used to refer to the ability that something or someone has an objective reason. And there are two examples for this kind of explanation.

6) When we have much money, we could use it to do many things.

7) Cars cause a lot of pollution but we can protect our cities from this pollution.

From the examples above, it's obvious that "can" and "could "are used to which allows the reader to accept the writer's views. In the first example the writer uses the word "could" to express the possibility of having money and indicates that the reason is objective. In the second example, the author states the fact that "Cars cause a lot of pollution", and uses the conjunction to express the idea that "We can not protect our cities from this pollution." Based on the above objective facts, the writer indirectly makes readers have no choice but to agree 
with his or her opinions and in this way he or she can achieve the writing purpose.

\section{b) Heuristic function}

Besides the pragmatic function, the different collocations of these two modal verbs "can" and "could" have heuristic function. After analyzing the data, it can be found that Chinese English learners use them to elaborate speculation about certain things and people. Based on the analysis of 50 English sentences selected from the search results and the specific context, we can see that Chinese English learners choose the collocations of these two modal verbs to express the possibility in a specific sentence. Here are examples:

1) Last but not least, it can be a waste of energy and money.

2) So when the young talk with the older, they nearly can not be comfortable.

3) Before they enter the college, their families protected them carefully, and they could not be blamed when they do wrong.

4) In my eye, a large number of people who are full of energy and kindness surround me, it's no doubt that I could be a better man under the positive impact of my friends.

From the example sentences above, it can be seen that different collocations of these two modal verbs are selected in the sentence to express different degrees of possibility and interact with readers. Actually, the writers use this kind of expression to inspire readers to think critically, which is a good way to convey the writers' writing proposes and persuade readers to support him or she. In the first example, the writer uses "can be" at the end of the sentence to indicate that it may be a waste of time and money after doing this, which guides readers to think about the impact of this event. In the second example, the writer explains that young people and old people may feel uncomfortable when they come into an unhappy situation. Obviously, this is also what the writer speculates about possible situations and try to give some hints that readers may suffer from this kind of situation and agree with her or his opinions, which triggers readers to pay attention to the question that what should people do when they have trouble communicating with each other and get to realize the importance of communication between the young and the old. And in the last example, the writers use the collocation of modal verb "could be" to make a prediction that the person who is always be with other people with high quality is prone to become a better man than before. The way the author has adopted in this sentence with some details to support the main idea makes the author's arguments more convincing.

\subsubsection{Certainty features}

From the heuristic function, it can be seen that Chinese English learners achieve the purpose of communicating with readers based on the possible meanings. Using school exams as a sub-database to search, it is found that different collocation forms express different possibilities in specific contexts, which also reflects that Chinese English learners use the collocation forms of these two modal verbs to indicate different degrees of speculation in different contexts. Chinese
English learners choose the possible meanings of these two modal verbs to explain their opinions, guide readers to think and then achieve the purpose of persuading readers. Generally speaking, although Chinese English learners use collocations with high possibility of expression in the process of writing, such as "can't be" or "couldn't be" to increase the readers" certainty. But in fact, the readers' certainty may decrease. The reason why this kind of situation may happen is that the higher possibilities the sentences have, the lower readers' certainty there are. In other words, the writers are subjective and they can't make all readers to accept his or her opinions about certain topics. Accordingly, Chinese English learners should fully consider whether the arguments in the composition are reasonable and avoid using completely absolute word to make the content of the article more convincing.

\section{Suggestions for the English Argumentative Writing}

According to the dictionary definition, we know that these two modal verbs "can" and "could" means several different meanings. It can be used as different collocations, including can't, couldn't, can be, could be, can't be, couldn't be, as well as this kind of special collocation- could have done / couldn't have done. As a result, in order to make students master the use of modal verbs "can" and "could" correctly, the author thinks that there are three points that English teachers should pay attention to during the process of English teaching.

The first point that the author puts forward is that the English teachers should stress the importance of learning these two modal verbs firstly and then guide students to make a contrast between these two modal verbs. For example, when the students start to learn how to use the modal verb "could", the English teachers can give some examples of sentences firstly and then let them find some differences among them. That is to say, the teachers cannot tell students the difference between the usage of "could". Of course, when the English teachers teach other language points about these two modal verbs, this kind of teaching method is also suitable.

The second point that the author emphasizes on is that the English teachers should pay attention to heuristic teaching, which means the English teachers should not only teach students some language points but also guide them to think critically. To achieve the goal, the English teachers don't need to point out to students which collocations of these modal verbs are more commonly used because there are no textbooks and dictionaries to show us the subtle differences in the specific use of these languages. So what kind of vocabulary is more suitable for the actual situation? The answer is that a large number of examples in the corpus can tell these differences. As a result, applying the corpus as a tool into English modal verbs teaching is a wise way to make students master them better. For Chinese English learners, it is not difficult to remember the common usage of the word because we have clear expressions in Chinese. But students do not grasp and understand the collocations that native speakers often use. Therefore, for learners of foreign languages, learning the collocation and context of the vocabulary is as important as knowing the meaning of the vocabulary. However, in traditional language learning process, learners are usually only required to master the meaning of these 
vocabulary and ignore how to use them correctly in the certain contexts, which has caused this kind of problem that the Chinese English learners are not confident to use different collocations of these two modal verbs "can" and "could" accurately. These following aspects can account for this problem. On the one hand, the teacher is limited by the textbook and there is no way to teach the students the language that can be used, which creates a vicious circle. On the other hand, the students don't master this part of language point very well.

The last point the author wants to highlight is that the English teachers should collect real language materials in life to make up for the shortcomings of these traditional textbooks and then apply what they have collected into the real English teaching. Namely, the birth of the corpus can help Chinese English learners solve this problem to a certain extent. It is believed that corpora can play an important role in the three links of textbook compilation, language teaching and students' self-study.

Firstly, English teachers can use the materials provided by a large corpus as the support and take the frequency of vocabulary, collocation and sentence patterns into account. Then the English teachers choose the proper example sentences as teaching material. But there is the most important thing that English teachers should pay attention to. That is that classic examples should keep pace with the times when the English teachers select the examples. Secondly, English teachers can use corpus to assist teaching in the process of organizing teaching. For example, when it comes to the English vocabularies teaching, English teachers are able to select some collocations that are often occurred and classic example sentences from the IWriteBaby corpus.

In this way, English teachers can use different specialized corpus in the different types of English lessons based on the actual teaching needs. For example, as for translation teaching, English teachers can use bilingual parallel corpus for translation comparison and language research. As a matter of fact, it's also a wise way for English teachers to improve their professional ability. Because English teachers can find that the differences between right and wrong answers that are matched with questions maybe lie in the actual frequency of language use when they make full use of corpus in the process of translation teaching. What's more, Chinese English learners are also be able to make the best of the corpus in their autonomous learning, such as using corpus and related retrieval tools to look up common word collocations, summarizing the context in which words are used to learn more useful English expressions. The last but not least, Chinese English learners can use corpus to check and verify whether their language output is correct after a long period of English learning compared with native speakers who have the English thinking habits.

\section{Conclusion}

In conclusion, this paper analyzes the characteristics of the use of modal verbs "can" and "could" in Chinese English Learners' argumentative writing based on the IWriteBaby corpus, which has found that there is a general tendency for Chinese English learners to use the modal verbs moderately.
First of all, compared with the modal verb "could", Chinese English learners is incline to using the modal verb "can" to express their ideas, which makes Chinese English learners' writing appear to be characterized by improper logic, low vocabulary richness, and insufficient arguments. In addition, Chinese English learners shows a downward trend in the overall distribution of the different collocations of the modal verbs "can" and "could" and often use the negative forms to show some different degrees of possibilities to restrict and communicate with readers. The specific order can be lined as follows: can't / couldn't $>$ can / could + be $>$ can't / couldn' $t+$ be, which also gives a hint that Chinese English learners have the characteristics of low dialogue, strong subjectivity, and weak logic in English argumentative writing. However, the sample size selected in this paper is small and there are certain subjective factors. Therefore, it can only provide some advice for English teaching based on the results of the research, such as leading students to make a contrastive learning between these two modal verbs, guiding learners to pay attention to the different collocations of modal verbs "can" and "could", and applying the specific modal verbs in the writing corpus into English writing teaching.

\section{References}

[1] Martin, J. R. \& P. R. White. The Language of Evaluation: Appraisal in English[M]. New York: Palgrave Macmillan, 2005.

[2] Lianqi Dong, Mei Li. A Corpus-based study on the Characteristics of Chinese English Learners Writing Assessment Resources $[\mathrm{J}]$. Foreign Language Audio-Visual Teaching, 2020(05): 86-93+13.

[3] Lianqi Dong. A Study of Interventional Chunks in Chinese English Learners' Arguments from the Perspective of Evaluation Theory[J]. Journal of PLA University of Foreign Languages, 2020, 43(04): 26-34.

[4] Qingnan Meng, Weihua Luo. A Multiple Quantitative Study on the Constructions of English Marginal Modal Verbs from the Perspective of Variation Linguistics: Taking Modal Need and Substantive Need as Example[J]. Foreign Language Teaching and Research, 2020, 52(05): 688-700+799.

[5] Xia Gao. Research on Modal Verbs Based on Comparable Corpus of Academic Papers by Chinese and Western Scholars[J]. Journal of PLA University of Foreign Languages, 2020, 43(05): 1-9+127+159.

[6] Jiajin Xu. Establishment of IWriteBaby Chinese English Learners Corpus[J]. Corpus Linguistics, 2019, 6(01): 105-109+117.

\section{Author Profile}

Bilian Zan (1995-), female, the Han nationality, Guangyuan, Sichuan Province, master, Southwest Petroleum University, graduate student, research area: Foreign Linguistics and Applied linguistics 